\title{
miR-433 protects pancreatic $\beta$ cell growth in high-glucose conditions
}

\author{
MIN WANG \\ Department of Endocrinology, Hunan Provincial People's Hospital, Changsha, Hunan 410005, P.R. China
}

Received June 7, 2016; Accepted April 10, 2017

DOI: $10.3892 / \mathrm{mmr} .2017 .6925$

\begin{abstract}
Pancreatic $\beta$ cell dysfunction is a key characteristic in the pathogenesis of diabetes mellitus (DM). MicroRNAs (miRNAs) havebeenidentified toservearoleinDMpathogenesis, but how specific miRNAs regulate glucose-stimulated $\beta$ cell functions remain unclear. The present study aimed to explore the effects of miR-433 on cell growth under high-glucose culture conditions and to determine the possible mechanisms involved. Reverse transcription-quantitative polymerase chain reaction (RT-qPCR) analysis was performed to detect the expression levels of miRNAs in Min- 6 pancreatic $\beta$ cells cultured in high-glucose medium, which revealed that miR-433 was significantly downregulated. Results from in vitro Cell Counting Kit-8, colony formation and flow cytometry analyses indicated that overexpression of miR-433 may enhance cell viability and proliferation by promoting cell cycle progression and suppressing apoptosis. Furthermore, bioinformatics prediction and luciferase analysis demonstrated that miR-433 was able to inhibit the expression of cyclooxygenase 2 (COX2) through targeting its 3'-UTR. Moreover, knockdown of COX2 expression alleviated the inhibition of cell growth induced by high glucose, similar to overexpression of miR-433. In conclusion, the present results suggested that miR-433 may protect pancreatic $\beta$ cells cultured in high glucose, which suggests that miR-433 may have beneficial effects in preventing and treating DM.
\end{abstract}

\section{Introduction}

Diabetes mellitus (DM) is characterized by elevated blood glucose levels (hyperglycemia) and has been identified as the most widespread metabolic disease worldwide (1). It is estimated that $>300$ million people are suffering from DM and this number is expected to reach 600 million by 2030 (2). The

Correspondence to: Dr Min Wang, Department of Endocrinology, Hunan Provincial People's Hospital, 61 Jiefangxi Road, Changsha, Hunan 410005, P.R. China

E-mail:wm4899@qq.com

Key words: pancreatic $\beta$ cells, miR-433, glucose, cyclooxygenase 2, cell proliferation rapidly increasing incidence of DM is one of the most challenging threats to public health in the 21st century. Despite some achievements for DM treatment, a variety of complications persist, such as endothelial dysfunction and retinopathy $(3,4)$. Therefore, a better understanding of the mechanisms of DM pathogenesis is of great clinical significance.

Pancreatic $\beta$ cell dysfunction has been reported to be the key process in the development and progression of DM; these cells are particularly sensitive to the glucose concentration under diabetic conditions (5-7). Hyperglycemia serves a direct role in inducing pancreatic $\beta$ cell apoptosis and decreasing $\beta$ cell proliferation (8). Dysfunctional $\beta$ cells result in low insulin secretion and subsequently accelerated development of DM (9). Therefore, it is vital to maintain a normal status of $\beta$ cells and to protect $\beta$ cell function, which will be important therapeutic targets for the treatment of DM $(10,11)$. Previous studies have focused on how to protect and improve functional $\beta$ cells to regulate glucose homeostasis in diabetes $(12,13)$; however, the exact mechanisms underlying glucose-induced pancreatic $\beta$ cell apoptosis and dysfunction remain largely unknown.

MicroRNAs (miRNAs) are a large class of small, non-coding single-stranded RNAs that have been demonstrated to be involved in the pathogenesis of many diseases, including cancers (14), bacterial and viral infections $(15,16)$ and diabetes (17). In addition, alterations in miRNA expression exert regulatory functions in posttranscriptional modification or degradation of their target genes by binding to complementary regions in the 3'-untranslated region (UTR) of their target mRNA transcripts $(18,19)$. Previous studies have demonstrated that miRNAs play a crucial role in pancreatic development and function. For example, miRNA (miR)-7 was the first to be reported to negatively regulate insulin secretion by $\beta$ cells (20), and miR-375 was revealed to negatively regulate glucose-stimulated insulin secretion by regulating the expression of myotrophin and phosphoinositide-dependent protein kinase $1(21,22)$. In addition, miR-96 was demonstrated to inhibit insulin secretion by targeting the expression of the Rab GTPase effector Noc2 (23). Other miRNAs, such as miR-7a, were also reported to potentially contribute to $\beta$ cell expansion during pancreatic organogenesis (24). In addition to these miRNAs, miR-433 expression was revealed to be downregulated in the visceral adipose tissues of patients with non-alcoholic steatohepatitis (25) and may act as a suppressor in human gastric carcinoma (26). Furthermore, miRNA 
profiling revealed miR-433 was downregulated in insulin 2-mutant diabetic Akita mice (27), suggesting that it may be closely related with diabetes pathogenesis.

The present study aimed to elucidate the biological functions and molecular target of miR-433 in pancreatic $\beta$ cells and to examine its role in a high-glucose environment. The results indicated that miR-433 may be able to protect mouse pancreatic $\beta$ cells against high-glucose-induced impairment of cell viability by directly targeting cyclooxygenase 2 [COX2; also known as prostaglandin-endoperoxide synthase 2 (PTGS2)] transcripts. Restoration of miR-433 expression may provide preliminary evidence for the clinical management of DM.

\section{Materials and methods}

Cell culture and glucose treatment. Min-6 mouse pancreatic $\beta$ cells and HEK293T cells were purchased from the Cell Bank of Type Culture Collection of the Chinese Academy of Sciences (Shanghai, China). All cells were cultured in Dulbecco's Modified Eagle's Medium (DMEM; HyClone; GE Healthcare Life Sciences, Logan, UT, USA) supplemented with $10 \%$ fetal bovine serum (FBS; Gibco; Thermo Fisher Scientific, Inc., Waltham, MA, USA). Cells were incubated in a humidified incubator at $37^{\circ} \mathrm{C}$ under $5 \% \mathrm{CO}_{2}$ atmosphere. The medium was replaced every other day.

Min- 6 cells were treated with either a low concentration of glucose (5 mmol/1; Sigma-Aldrich; Merck KGaA, Darmstadt, Germany) or a high concentration of glucose $(11 \mathrm{mmol} / \mathrm{l}$; the high-glucose group) for $24 \mathrm{~h}$. The high-glucose group was further divided for subsequent miR-433 overexpression analysis, as detailed below.

Transient transfection with miRNA mimics or siRNA. Mouse miR-433 mimics and negative controls (NC), and COX2 short interfering (si)RNA (siCOX) and siRNA negative control were obtained from Shanghai GenePharma Co., Ltd. (Shanghai, China). The sequences were as follows: miR-433 mimic, sense 5'-AUCAUGAUGGGCUCCUCGGUGU-3'; siCOX, sense 5'-GACCCAAGCAUGUUAUAAAUU-3'; siRNA-NC and mimics-NC, 5'-CAGUACUUUGUGUAGUACAA-3'. For transfection, Min- 6 cells $\left(2 \times 10^{5}\right.$ cells/well) were cultured in a 6 -well plate and transiently transfected at $\sim 80 \%$ confluence with $50 \mathrm{nM}$ siCOX and $\mathrm{NC}$ for $48 \mathrm{~h}$ at $37^{\circ} \mathrm{C}$ using Lipofectamine 2000 reagent (cat. no. 52887; Invitrogen; Thermo Fisher Scientific, Inc.), according to the manufacturer's protocol.

In addition, according to the manufacturer's protocol, Min-6 cells $\left(2 \times 10^{5}\right.$ cells/well) seeded in 6-well plates were transfected with $200 \mu \mathrm{l}$ mature miR-433 mimic (100 $\mathrm{nM})$ and $\mathrm{NC}(100 \mathrm{nM})$ for $48 \mathrm{~h}$ at $37^{\circ} \mathrm{C}$ using Lipofectamine 2000 reagent (Invitrogen; Thermo Fisher Scientific, Inc.) for $72 \mathrm{~h}$. Successful transfection was confirmed using reverse transcription-quantitative polymerase chain reaction (RT-qPCR). The primers used were as follows: miR-433, forward 5'-GGGATC ATGATGGGCTCCTCG-3' and reverse 5'-CTCAACTGG TGTCGTGGA-3'.

$R N A$ isolation and reverse transcription-quantitative polymerase chain reaction ( $R T-q P C R)$. Total RNA was isolated from cells $\left(2 \times 10^{6}\right)$ using the mirVana miRNA Isolation kit
(Ambion; Thermo Fisher Scientific, Inc.), according to the manufacture's protocol. RNA purity was measured photometrically using a NanoDrop spectrophotometer (Thermo Fisher Scientific, Inc., Wilmington, DE, USA). The optical density $(\mathrm{OD})_{260 / 280}$ ratio was used as an indicator for RNA purity. A ratio $>1.8$ was assumed as suitable for gene expression measurements. Total RNA was reverse transcribed into cDNA using the RevertAid First Strand cDNA Synthesis kit (cat no. K1622; Thermo Fisher Scientific, Inc.) according to the manufacturer's protocol. For miRNA expression analysis, $200 \mathrm{ng}$ of total RNA were isolated from Min-6 and HEK293T cells and reverse transcribed into cDNA using the RevertAid First Strand cDNA Synthesis kit (Thermo Fisher Scientific, Inc.). qPCR was performed using SYBR Green PCR Master Mix (Applied Biosystems; Thermo Fisher Scientific, Inc.) on the on the ABI HT9600 system (Applied Biosystems; Thermo Fisher Scientific, Inc.). The reaction volume was $10 \mu \mathrm{l}$ and contained the following: $5 \mu \mathrm{l}$ SYBR-Green PCR Master Mix, $10 \mu \mathrm{M}(0.4 \mu \mathrm{l})$ of each forward and reverse primer, $0.2 \mu \mathrm{l}$ ROX reference dye, $1 \mu \mathrm{l}$ cDNA template and $3 \mu \mathrm{ldd} \mathrm{H}_{2} \mathrm{O}$. Thermocycling conditions were as follows: Initial 1 step at $95^{\circ} \mathrm{C}$ for $10 \mathrm{~min}$, followed by 40 cycles at $95^{\circ} \mathrm{C}$ for $15 \mathrm{sec}$ and at $60^{\circ} \mathrm{C}$ for $60 \mathrm{sec}$. Relative gene expression was calculated using the comparative $\mathrm{Cq}$ method (28), and miR-433, miR-199-5p, miR-30a and miR-22 expression was normalized to U6, whereas COX2 expression was normalized to $\beta$-actin. The following primers were in the present study: miR-433, forward 5'-GGGATCATGATGGGCTCCTCG-3'; miR-199-5p, forward 5'-CTGGGCCCAGTGTTCAGACTA CCT-3'; miR-30a, forward 5'-GCTGGGTGTAAACATCCT CG-3'; and miR-22, forward 5'-GCTGGGAAGCTGCCAGTT GAAG-3'; each forward primer was used in combination with the universal miRNA reverse primer, 5'-CTCAACTGGTGT CGTGGA-3'; COX2, forward 5'-AGATGACTGCCCAAC TCCCA-3', reverse 5'-TGAACCCAGGTCCTCGCTTA-3'; U6, forward 5'-CTCGCTTCGGCAGCACA-3', reverse 5'-AAC GCTTCACGAATTTGCGT-3'; and $\beta$-actin, forward 5'-CAT TGCTGACAGGATGCAGA-3' and reverse 5'-CTGCTGGAA GGTGGACAGTGA-3'.

Western blot analysis. Total proteins were isolated from cells $\left(2 \times 10^{6}\right)$ using radioimmunoprecipitation assay lysis buffer (Sigma-Aldrich; Merck KGaA) supplemented with a protease inhibitor cocktail (cat no. P8340; Sigma-Aldrich; Merck $\mathrm{KGaA}$ ) for $5 \mathrm{~min}$ on ice, and then centrifuged at 13,000 x g for $20 \mathrm{~min}$ at $4^{\circ} \mathrm{C}$. Protein concentration was determined using a bicinchoninic acid assay kit (Bio-Rad Laboratories, Inc., Hercules, CA, USA), according to the manufacturer's protocol. Equal amounts of extracted protein samples $(30 \mu \mathrm{g})$ were separated by $10 \%$ SDS-PAGE and transferred onto polyvinylidene difluoride membranes, which were then blocked for $2 \mathrm{~h}$ with $5 \%$ non-fat dry milk and incubated at $4{ }^{\circ} \mathrm{C}$ overnight with primary antibodies against COX2 (cat no. 12282; 1:1,000; Cell Signaling Technology, Inc., Danvers, MA, USA) or GAPDH (cat no. 5174; 1:1,000; Cell Signaling Technology, Inc.). Membranes were then incubated for $1 \mathrm{~h}$ at room temperature with the following horseradish peroxidase-conjugated secondary antibodies: goat anti-mouse immunoglobulin (Ig) G (cat no. SC-2005; 1:1,000; Santa Cruz Biotechnology, Inc., Dallas, TX, USA) and goat anti-rabbit IgG (cat no. SC-2004; 
1:1,000; Santa Cruz Biotechnology, Inc.). Protein bands were visualized using the Enhanced Chemiluminescence Western Blotting Analysis System (Pierce; Thermo Fisher Scientific, Inc.). Data were analyzed using the Image Lab software version 4.1 (Bio-Rad Laboratories, Inc.).

Dual luciferase assays. StarBASE software version 2.0 (http://starbase.sysu.edu.cn/panCancer.php) was used to identify potential target genes for miR-433; results indicated that the COX2 gene contained a potential miR-433 binding site in its 3'-UTR. To confirm whether miR-433 directly binds to COX2 3'-UTR, a dual luciferase assay was performed. Genomic DNA was extracted using the QIAamp DNA Mini kit (Qiagen, Inc., Valencia, CA, USA) according to the manufacturer's protocol. The COX2 3'-UTR sequence (length, $779 \mathrm{bp}$ ) was amplified by PCR from genomic DNA using the GoTaq ${ }^{\circledR}$ Long PCR Master Mix (Promega Corporation, Madison, WI, USA). The following primers were used: COX2 3'UTR, forward 5'-CCCTCGAGTCATTCCTCTACA TAAGCCAGTG-3' and reverse 5'-ATTTGCGGCCGCGAG TACCAGGCCAGCACAA-3'. Thermocycling conditions were as follows: Pre-denaturation at $95^{\circ} \mathrm{C}$ for $2 \mathrm{~min}$, followed by 30 cycles of denaturation at $95^{\circ} \mathrm{C}$ for $30 \mathrm{sec}$, annealing at $60^{\circ} \mathrm{C}$ for $30 \mathrm{sec}$ and extension at $72^{\circ} \mathrm{C}$ for $45 \mathrm{sec}$, and a final extension step at $72^{\circ} \mathrm{C}$ for $5 \mathrm{~min}$. COX2 $3^{\prime}$-UTR mutants were generated using the Site-Directed Mutagenesis kit (Yeasen Biological Technology Co., Ltd., Shanghai, China), according to the manufacturer's protocol. Following amplification, the PCR products were digested with $\mathrm{XbaI}$ and $\mathrm{KpnI}$ restriction enzymes (New England BioLabs, Inc., Ipswich, MA, USA) for at least $3 \mathrm{~h}$ and purified using the QIAquick PCR purification kit (Qiagen, Inc.) according to the manufacturer's protocol. The purified sequences were then inserted into a psiCHECK-2 reporter plasmid (Guangzhou RiboBio Co., Ltd., Guangzhou, China). The purified vector and PCR products were ligated overnight at $16^{\circ} \mathrm{C}$ using T4 DNA ligase $(1 \mu 1,400 \mathrm{U} / \mu 1$; cat no. EL0012; Thermo Fisher Scientific, Inc.), at a ratio of 1:3 in $2 \mu \mathrm{l} 10 \mathrm{X}$ ligation buffer. The mutation in the miR-433 binding site of the COX2 3'-UTR was confirmed by Shanghai Shenggong Biology Engineering Technology Service, Ltd., Shanghai, China). For the luciferase assay, HEK293T cells at a density of $5 \times 10^{4}$ cells/well were seeded in 24-well plates and transfected with the luciferase reporter plasmid $(0.4 \mu \mathrm{g} / \mu \mathrm{l})$ along with miR-433 mimics $(50 \mathrm{nM})$ or negative control $(50 \mathrm{nM})$ and a Renilla luciferase control reporter vector $(0.218 \mu \mathrm{g} / \mu \mathrm{l}$; pRL-SV40; Promega Corporation) using Lipofectamine 2000 (Invitrogen; Thermo Fisher Scientific, Inc.). Following $24 \mathrm{~h}$ of transfection, luciferase activities were measured using a Luciferase Assay kit (Promega Corporation) and a GloMax ${ }^{\circledR} 96$ microplate luminometer (Promega Corporation), according to the manufacturer's protocol.

Cell viability assay. The Cell Counting kit 8 (CCK8) assay was used to determine the viability of the Min- 6 cells in the following treatment groups: $5 \mathrm{mmol} / 1$ glucose, $11 \mathrm{mmol} / 1$ glucose, $11 \mathrm{mmol} / 1$ glucose and siCOX2, $11 \mathrm{mmol} / 1$ glucose and mimics, and $11 \mathrm{mmol} / 1$ glucose and NC. Briefly, cells ( $3 \times 10^{3}$ cells/well) were seeded in a 96-well plate and incubated in $10 \%$ CCK8 solution (Shanghai 7Sea PharmTech Co. Ltd.,
Shanghai, China) solution for $2 \mathrm{~h}$ at $37^{\circ} \mathrm{C}$. Proliferation rates were determined at $0,12,24,48$, and $72 \mathrm{~h}$ post-treatment. The absorbance of each well was measured at $490 \mathrm{~nm}$ using using a Synergy HTX Multi-Mode Microplate Reader (BioTek Instruments, Inc., Winooski, VT, USA). Each experiment was performed in triplicate.

Colony formation assay. Min- 6 cells $\left(2 \times 10^{3}\right.$ cells) from different treatment groups were seeded in a $10-\mathrm{cm}$ cell culture dish and cultured in DMEM (HyClone; GE Healthcare Life Sciences) supplemented with 10\% FBS (Gibco; Thermo Fisher Scientific,Inc.) for 10 days at $37^{\circ} \mathrm{C}$ and $5 \% \mathrm{CO}_{2}$ until the colonies were visible. Min- 6 cells were treated with a low concentration of glucose ( $5 \mathrm{mmol} / \mathrm{l}$ group) or a high concentration of glucose (11 mmol/1 group); high glucose-treated cells were treated with miR-433 mimic (11 mmol/1 + mimics group), COX2 siRNA (11 mmol/1 + siCOX2 group) or NC siRNA (11 mmol/1 + siNC group). Following incubation for $24 \mathrm{~h}$, the medium was removed and the plates were washed twice in PBS. Colonies were fixed in $95 \%$ ethanol for $10 \mathrm{~min}$ at room temperature, air-dried for $10 \mathrm{~min}$ at room temperature and stained with $0.1 \%$ crystal violet solution for $10 \mathrm{~min}$ at room temperature. Colonies containing $>50$ cells were directly identified by their size and counted. The experiment was performed three times.

Flow cytometric analysis. Min-6 cells were treated with $5 \mathrm{mmol} / 1$ glucose, $11 \mathrm{mmol} / 1$ glucose, $11 \mathrm{mmol} / 1$ glucose and COX2 siRNA (11 mmol/1 + siCOX2 group), $11 \mathrm{mmol} / 1$ glucose and NC (11 mmol/1 + NC group), or $11 \mathrm{mmol} / 1$ glucose and miR-433 mimic (11 mmol/1 + mimics group) for $24 \mathrm{~h}$. Min- 6 cells $\left(1 \times 10^{6}\right.$ cells $\left./ \mathrm{ml}\right)$ from the different treatment groups were used for apoptosis and cell cycle analysis with the Dead Cell Apoptosis Kit with Annexin $\mathrm{V}$, fluorescein isothiocyanate (FITC) and propidium iodide (PI), for flow cytometry (Invitrogen, U.S.A; Thermo Fisher Scientific, Inc.), according to the manufacturer's protocol. Briefly, cells were harvested by trypsinization, resuspended in $500 \mu \mathrm{l}$ binding buffer and stained with $5 \mu \mathrm{l}$ Annexin V-FITC and $5 \mu \mathrm{l}$ PI solution for $30 \mathrm{~min}$ at room temperature in the dark. Samples were immediately analyzed for apoptosis using a FACSCalibur flow cytometer (BD Biosciences, Franklin Lakes, NJ, USA). For cell cycle analysis, the cells were fixed in ice cold $70 \%$ (v/v) ethanol overnight, resuspended in $500 \mu \mathrm{l} \mathrm{PBS}$ containing $50 \mathrm{mg} / \mathrm{ml}$ RNase (Sigma-Aldrich; Merck KGaA ) and incubated at $37^{\circ} \mathrm{C}$ for $30 \mathrm{~min}$. Following staining with $50 \mathrm{mg} / \mathrm{ml} \mathrm{PI}$ (Sigma-Aldrich; Merck $\mathrm{KGaA}$ ) at $4^{\circ} \mathrm{C}$ in the dark for $30 \mathrm{~min}$, cell cycle distribution was analyzed using a FACSCalibur flow cytometer (BD Biosciences). Each sample was analyzed using Flowing Software version 2.5.0 (http://flowingsoftware.btk.fi/index. php?page=1) in triplicate.

Statistical analysis. Data were analyzed using SPSS software, version 13.0 (SPSS Inc., Chicago, IL, USA) and expressed as the mean \pm standard deviation of $>3$ samples. The statistical significance of the differences between groups was assessed using one-way analysis of variance followed by a post hoc Bonferroni test for multiple comparisons. $\mathrm{P}<0.05$ was considered to indicate a statistically significant difference. 


\section{Results}

miR-433 expression is inhibited under high glucose conditions, and miR-433 directly targets COX2 in pancreatic $\beta$ cells. As shown in Fig. 1A, Min-6 cell viability was significantly inhibited in high-glucose condition $(11 \mathrm{mmol} / \mathrm{l})$ compared with low-glucose condition $(5 \mathrm{mml} / 1 ; \mathrm{P}<0.001)$. miRNAs, including miR-433, miR-199-5p, miR-30a and miR-22, have been reported to serve an important role in hyperglycemia $(29,30)$. Therefore, the expression levels of several miRNAs were examined in Min- 6 cells cultured in high-glucose or low-glucose. Notably, the expression level of miR-433 was significantly lower in high-glucose-induced Min-6 cells, whereas the expression level of miR-22 was significantly higher in high-glucose-induced Min- 6 cells $(\mathrm{P}<0.001$ and $\mathrm{P}<0.01$, respectively; Fig. 1B). Since the change in miR-433 expression appeared to be the most profound, miR-433 was further investigated. Bioinformatics analysis was used to identify potential target genes for miR-433, which indicated that COX 2 contained a potential miR-433 binding site in the 3'-UTR (Fig. 1C). To further confirm whether COX2 was directly regulated by miR-433, a wild-type and a mutated version of the COX2 3'-UTR was cloned and inserted into luciferase reporter constructs. Co-transfection with miR-433 mimics significantly reduced luciferase activity in reporter constructs containing the wild-type COX 2 3'-UTR $(\mathrm{P}<0.01$; Fig. 1D), while there was no change in luciferase activity following mutation of the potential miR-433 binding site.

The effects of miR-433 overexpression on endogenous COX2 expression were also examined in Min- 6 cells under normal glucose conditions ( $5 \mathrm{mmol} / \mathrm{l})$; compared with the control cells, endogenous COX2 mRNA levels were significantly reduced in Min- 6 cells transfected with miR-433 mimics $(\mathrm{P}<0.001$; Fig. 1E). The levels of COX2 mRNA expression were significantly increased in high-glucose-induced Min-6 cells compared with cells in the low-glucose treatment group $(\mathrm{P}<0.001$; Fig. 1F). These results suggested that $\mathrm{COX} 2$ was overexpressed in Min- 6 cell cultured in high-glucose condition and that COX2 may be a target of miR-433.

miR-433 stimulates pancreatic $\beta$ cell proliferation. To investigate the potential roles of miR-433 on Min- 6 cell proliferation, Min- 6 cells were first transfected with miR-433 mimics. Endogenous COX2 protein expression was reduced in Min- 6 cells treated with siCOX2, as determined by western blot analysis (Fig. 2A). Results from the CCK-8 assay indicated that both miR-433 mimics and siCOX2 treatments alleviated cell growth inhibition in Min- 6 cells cultured in high-glucose conditions (Fig. 2B; $\mathrm{P}<0.001$ ). Consistently, the colony formation capabilities of Min- 6 cells were inhibited in high-glucose conditions, whereas treatment with either miR-433 mimics or siCOX2 significantly enhanced the colony forming ability in Min- 6 cells cultured in high-glucose conditions (Fig. 2C and D; $\mathrm{P}<0.001$ ). These results suggested that the glucose-induced reduction in Min- 6 cell proliferation may be reversed following COX 2 inhibition or miR-433 overexpression. Therefore, these results suggested that miR-433 overexpression may be able to promote pancreatic $\beta$ cell proliferation in Min- 6 cells grown in a high-glucose environment.
miR-433 alleviated apoptosis and cell cycle arrest induced by high-glucose. To further uncover the mechanisms underlying the improved cell proliferation induced by miR-433 in pancreatic $\beta$ cells treated with high-glucose, the effects of miR-433 mimics on apoptosis were examined using a flow cytometry apoptosis assay. Both miR-433 mimics and siCOX2 treatments caused significant changes in the profiles of Annexin V-FITC/PI-stained cell populations. The apoptotic rate of the miR-433 mimics and siCOX2 groups appears to be much lower compared with the NC group (Fig. 3A) Statistical analysis further demonstrated that both miR-433 mimics and siCOX 2 treatments significantly reduced the level of high-glucose-induced apoptosis in Min- 6 cells $(\mathrm{P}<0.001$; Fig. 3B). In addition, flow cytometric analysis was used to characterize cell cycle behavior of Min- 6 cells treated with siCOX2 or miR-433 mimics. The distribution of cells in the phases of the cell cycle $\left(\mathrm{G}_{0} / \mathrm{G}_{1}, \mathrm{~S}\right.$ and $\left.\mathrm{G}_{2} / \mathrm{M}\right)$ varied between the different treatment groups (Fig. 4A). Compared with the NC group, miR-433 overexpression and treatment with siCOX2 led to a significant increase in the percentage of cells in $\mathrm{G}_{2} / \mathrm{M}$ phase and a reduction in $\mathrm{G}_{0} / \mathrm{G}_{1}$ phase cells $(P<0.001$; Fig. 4B). Based on these results, the present study speculated that miR-433 could alleviate high-glucose-induced growth inhibition in pancreatic $\beta$ cells through regulating cell cycle and apoptosis.

\section{Discussion}

The proliferative and regenerative capacity of pancreatic $\beta$ cells is known to be closely associated with the quantity of insulin released; there is a feedback loop between insulin secretion and the concentration of glucose in the blood (31). In this regard, it is important to improve pancreatic $\beta$ cell function and survival under proapoptotic conditions to design innovative therapeutics for DM. In the present study, Min- 6 cells grown in high-glucose medium exhibited more suppressive effects on $\beta$ cell viability and proliferation compared with cells grown in low-glucose conditions, which is consistent with a previous study (8). In addition, significant increases in apoptosis and cell cycle arrest at G2/M phase were noted in $\beta$ cells cultured with high-glucose compared with those grown in low-glucose media.

To further investigate the mechanisms underlying the high-glucose-induced $\beta$ cell growth inhibition, several concentrations of glucose in $\beta$ cells were screened. The expression of miR-433 was revealed to be downregulated in high-glucose-induced Min-6 cells, whereas the expression of miR-22 was upregulated. However, further studies are required to validate the results regarding miR-22 expression and to investigate its effects in pancreatic $\beta$ cells.

In the present study, miR-433 expression was demonstrated to be downregulated in high-glucose treatments and its overexpression by miRNA-433 mimics transfection significantly promoted cell viability and proliferation in high-glucose conditions by suppressing apoptosis and enhancing cell cycle progression. Previous studies have reported that miR-433 is downregulated in various cancer tissues, such as bladder cancer and oral squamous cell carcinomas $(32,33)$, which indicated that miR-433 may have a tumor-suppressor function in carcinomas. Notably, the expression levels of miR-433 were 

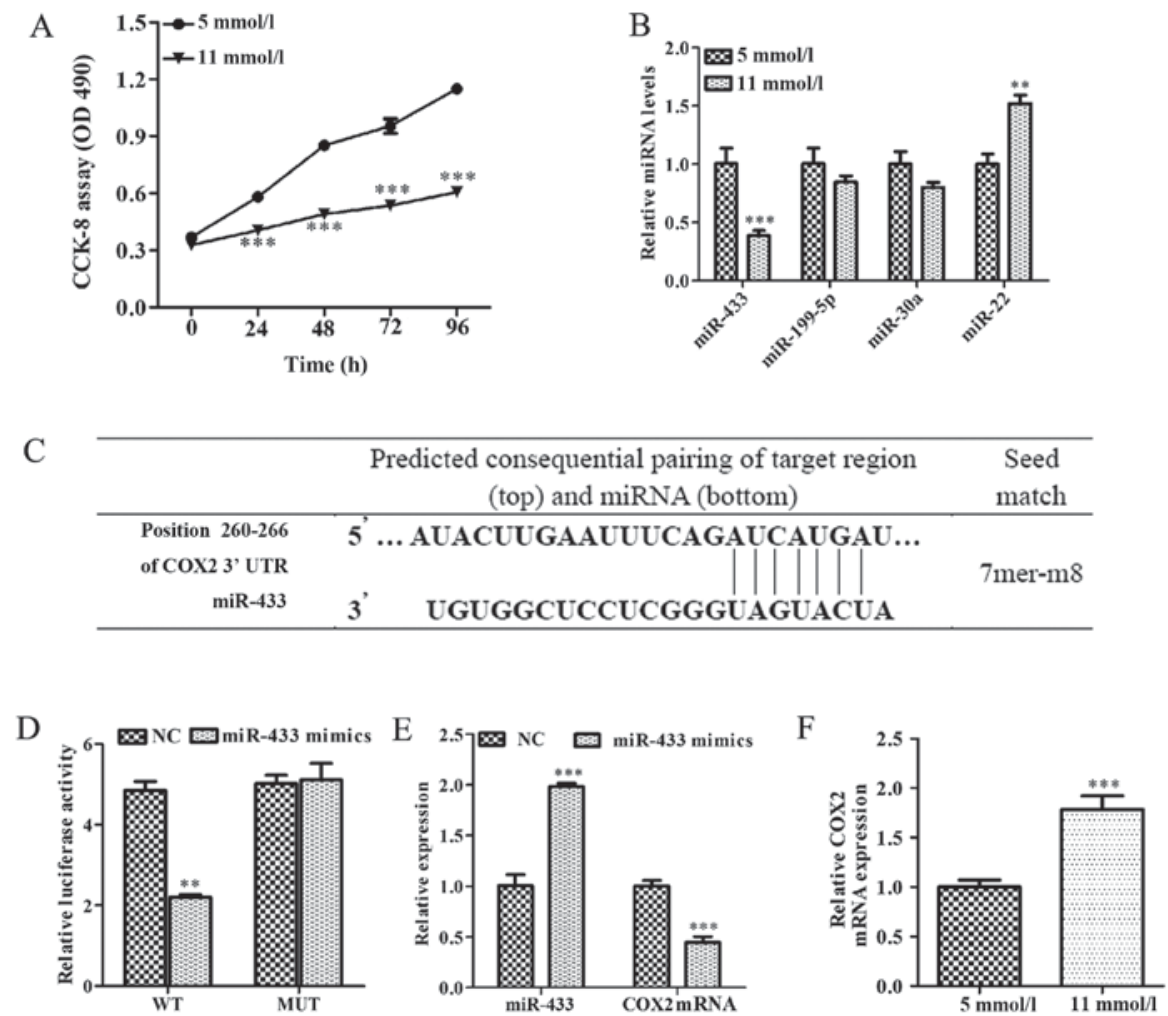

Figure 1. miR-433 is associated with cell growth inhibition induced by high glucose, and miR-433 negatively regulates COX2 expression in Min- 6 pancreatic $\beta$ cells. (A) CCK-8 assay was used to determine cell viability in Min- 6 cells treated with either a low $(5 \mathrm{mmol} / \mathrm{l})$ or a high (11 mmol/1) concentration of glucose for 24 h. (B) Expression levels of miR-433, miR-199-5p, miR-30a and miR-22 were analyzed by RT-qPCR in Min- 6 cells treated with either 5 mmol/1 or $11 \mathrm{mmol} / \mathrm{l}$ glucose. (C) Bioinformatics prediction of miR-433 binding site in the 3'-UTR of COX2 mRNA. (D) HEK293T cells were co-transfected with a WT or a MUT COX 3'-UTR reporter plasmid along with miR-433 mimics or NC mimics. Activity was measured by dual luciferase reporter assay and presented as relative luciferase activity. (E) COX2 mRNA expression levels were detected by RT-qPCR in Min- 6 cells cultured in high glucose conditions following transfection with miR-433 mimics. (F) mRNA levels of COX2 were determined by RT-qPCR in Min- 6 cells treated with $5 \mathrm{mmol} / 1$ or $11 \mathrm{mmol} / 1 \mathrm{glucose}$. Data are expressed as the mean \pm standard deviation; ${ }^{* *} \mathrm{P}<0.01$ and ${ }^{* * *} \mathrm{P}<0.001$ vs. low-glucose treatment or NC. CCK- 8 , Cell Counting Kit-8; COX2, cyclooxygenase 2; miR, microRNA; miRNA, microRNA; Mmu, Mus musculus; MUT, mutant; RT-qPCR, reverse transcription-quantitative polymerase chain reaction; UTR, untranslated region; WT, wild-type.

A

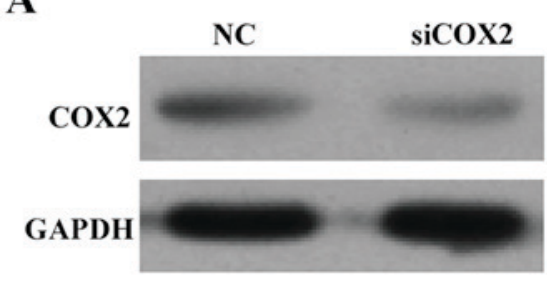

C

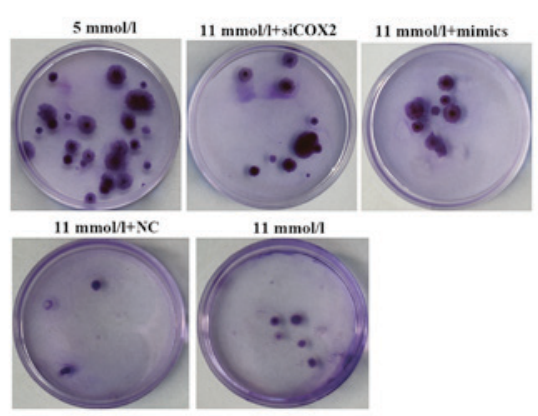

B

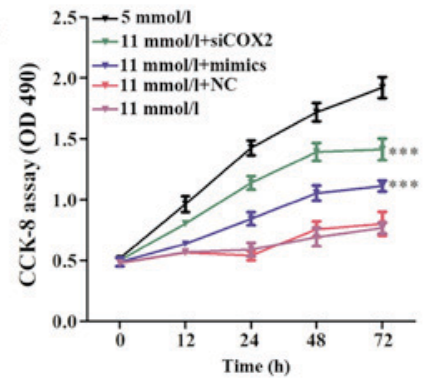

D

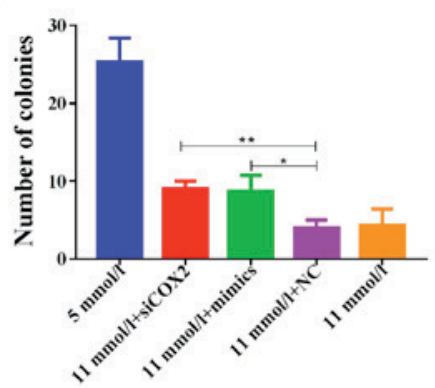

Figure 2. Overexpression of miR-433 increases the proliferation of Min- 6 pancreatic $\beta$ cells cultured in high-glucose conditions. (A) COX2 protein expression was decreased in Min- 6 cells following transfection with siCOX2. (B) CCK-8 assay was used to determine the viability of Min- 6 cells in different treatment groups. (C) Representative images demonstrating the colony forming ability in Min-6 cells from the different treatment groups. (D) Quantitation of colonies with $>50$ cells from (C). Data are expressed as the mean \pm standard deviation; ${ }^{* * * *} \mathrm{P}<0.001 \mathrm{vs.} 11 \mathrm{mmol} / 1+\mathrm{NC}$. CCK-8, Cell Counting Kit-8; COX2, cyclooxygenase 2; miR, microRNA; siCOX2, COX2-directed siRNA; NC, negative control siRNA; siRNA, short interfering RNA. 

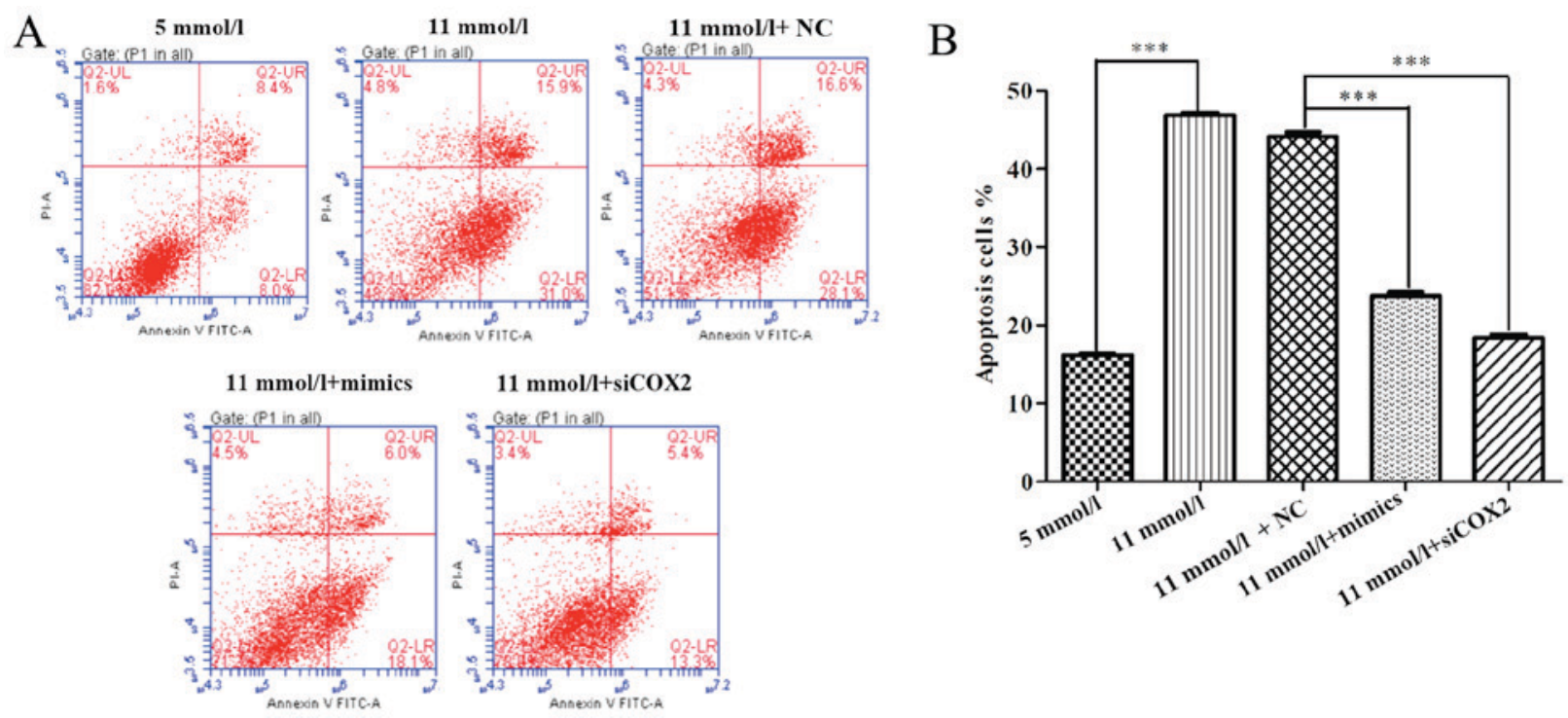

Figure 3. Overexpression of miR-433 inhibits apoptosis in Min-6 pancreatic $\beta$ cells induced by high-glucose. (A) Apoptosis of Min-6 cells transfected with miR-433 mimics or siCOX2 cells and cultured in $5 \mathrm{mmol} / 1$ or $11 \mathrm{mmol} / 1$ glucose following Annexin-V-FITC/PI staining and flow cytometric analysis. (B) Statistical analysis of apoptotic cells in (A) from Min-6 cells exposed to different treatments. Data are expressed as the mean \pm standard deviation; ${ }^{* * *} \mathrm{P}<0.001$. COX2, cyclooxygenase 2; FITC, fluorescein isothiocyanate; miR, microRNA; PI, propidium iodide; siCOX2, COX2-directed siRNA; NC, negative control siRNA; siRNA, short interfering RNA.
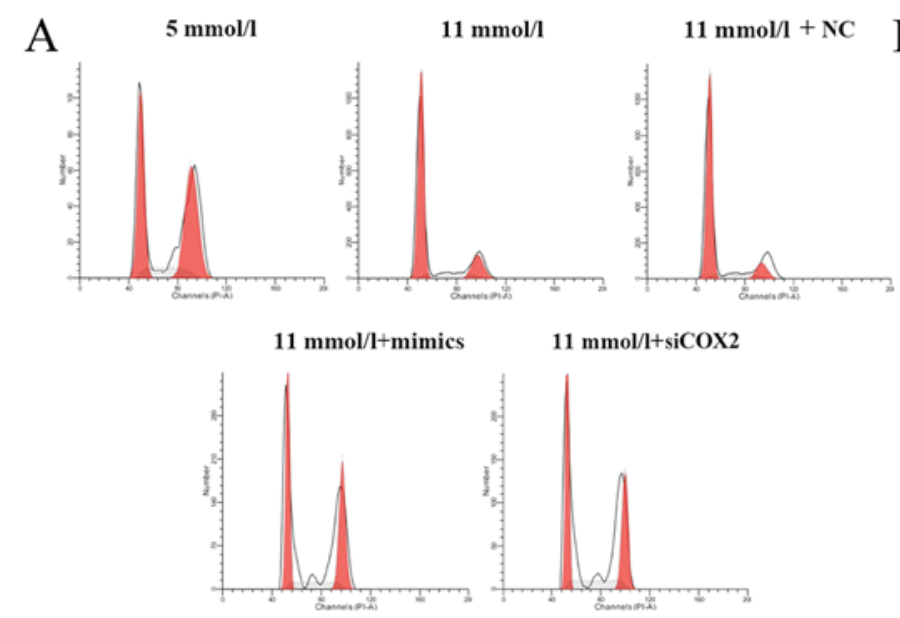

$11 \mathrm{mmol} / \mathrm{l}+\mathrm{siCOX} 2$

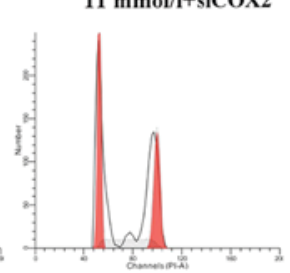

\section{B}

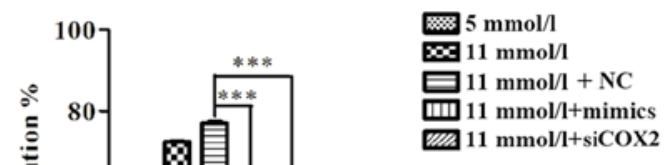

X0. $11 \mathrm{mmo}$

שूa $11 \mathrm{mmol} / \mathrm{siCOX2}$

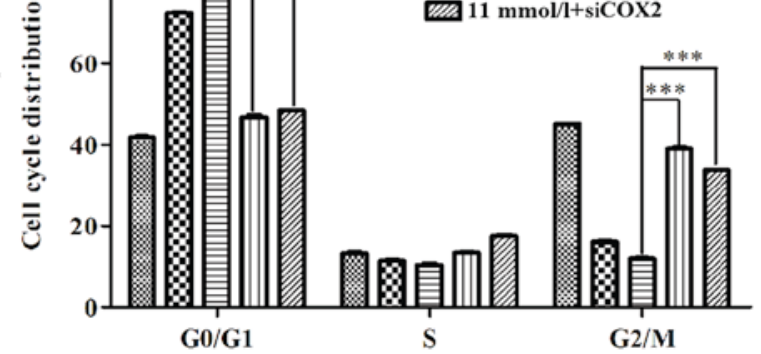

Figure 4. Overexpression of miR-433 alleviates cell cycle arrest in Min-6 cells induced by high-glucose. (A) Cell cycle was determined in Min-6 cells from different treatments by flow cytometry. (B) Statistical analysis of the percentages of cells in the G0/G1, S and G2/M cell cycle phases in Min-6 cells from different treatments shown in (A). Data are expressed as the mean \pm standard deviation; ${ }^{* * *} \mathrm{P}<0.001$. COX2, cyclooxygenase 2; miR, microRNA; PI, propidium iodide; siCOX2, COX2-directed siRNA; NC, negative control siRNA; siRNA, short interfering RNA.

revealed to be reduced in renal tissues of pancreatic kininogenase-treated patients with diabetic nephropathy (34). miR-433 may negatively regulate the expression of thymidylate synthase in HeLa cells (35), suggesting a role in metabolism regulation, thus possibly modulating the glucose metabolism.

Furthermore, the present study identified and validated COX 2 as a potential target of miR-433, which suggested that miR-433 may participate in $\beta$ cell biology by regulating COX 2 expression. COX 2 is an important enzyme involved in the production of prostaglandin E2 (PGE2) and arachidonic acid (36). PGE2, as a COX2-generated metabolite, protects $\beta$ cells from apoptosis (37). Results from the present study indicated that COX2 was overexpressed in Min- 6 cells cultured in high-glucose compared with cells grown in low-glucose conditions. Knockdown of COX2 by siRNA was demonstrated to alleviate the high-glucose-induced inhibition of cell proliferation by suppressing apoptosis and promoting cell cycle progression. According to a recent report, $\mathrm{COX} 2$ was enhanced by the overexpression of p50 following exposure to an inflammatory mediator in DM (38). Moreover, inhibition of COX2 has been demonstrated to be a promising antitumor therapy in renal cell carcinoma (39).

In summary, the expression level of miR-433 decreased, whereas the level of COX2 mRNA increased in Min-6 mouse pancreatic $\beta$ cells cultured in high-glucose medium; results from in vitro analyses indicated that miR-433 may promote pancreatic $\beta$ cell growth by regulating COX2 expression. Results from the present study may provide information regarding novel therapeutic targets for DM. 


\section{References}

1. Sheik Abdulazeez S: Diabetes treatment: A rapid review of the current and future scope of stem cell research. Saudi Pharm J 23: 333-340, 2015

2. Scully T: Diabetes in numbers. Nature 485: S2-S3, 2012.

3. Sikorska D, Pawlaczyk K, Olewicz-Gawlik A, Czepulis N, Posnik B, Baum E, Wanic-Kossowska M, Lindholm B and Oko A: The importance of residual renal function in peritoneal dialysis. Int Urol Nephrol 48: 2101-2108, 2016.

4. Abbasakoor NO, Healy ML, O'Shea D, Maguire D, Muldoon C, Sheahan K and O'Toole D: Metastatic insulinoma in a patient with type 2 diabetes mellitus: Case report and review of the literature. Int J Endocrinol 2011: 124078, 2011.

5. American Diabetes Association: Diagnosis and classification of diabetes mellitus. Diabetes care 37 (Suppl 1): S81-S90, 2014.

6. Prentice KJ, Luu L, Allister EM, Liu Y, Jun LS, Sloop KW, Hardy AB, Wei L, Jia W, Fantus IG, et al: The furan fatty acid metabolite CMPF is elevated in diabetes and induces $\beta$ cell dysfunction. Cell Metab 19: 653-666, 2014.

7. Rutter GA, Pullen TJ, Hodson DJ and Martinez-Sanchez A: Pancreatic $\beta$-cell identity, glucose sensing and the control of insulin secretion. Biochem J 466: 203-218, 2015.

8. Wang S, Yang Z, Gao Y, Li Q, Su Y, Wang Y, Zhang Y, Man H and Liu H: Pyruvate kinase, muscle isoform 2 promotes proliferation and insulin secretion of pancreatic $\beta$-cells via activating Wnt/CTNNB1 signaling. Int J Clin Exp Pathol 8: 14441-14448, 2015.

9. Tangvarasittichai S: Oxidative stress, insulin resistance, dyslipidemia and type 2 diabetes mellitus. World J Diabetes 6: 456-480, 2015.

10. Del Prato S, Bianchi C and Marchetti P: beta-cell function and anti-diabetic pharmacotherapy. Diabetes Metab Res Rev 23: 518-527, 2007.

11. Vetere A, Choudhary A, Burns SM and Wagner BK: Targeting the pancreatic $\beta$-cell to treat diabetes. Nat Rev Drug Discov 13: 278-289, 2014

12. Santulli G, Pagano G, Sardu C, Xie W, Reiken S, D'Ascia SL, Cannone M, Marziliano N, Trimarco B, Guise TA, et al: Calcium release channel RyR2 regulates insulin release and glucose homeostasis. J Clin Invest 125: 4316, 2015.

13. Prabhakar PK and Doble M: Mechanism of action of natural products used in the treatment of diabetes mellitus. Chin J Integr Med 17: 563-574, 2011.

14. Hwang HW and Mendell JT: MicroRNAs in cell proliferation, cell death, and tumorigenesis. Br J Cancer 94: 776-780, 2006.

15. Sullivan CS and Ganem D: MicroRNAs and viral infection. Mol Cell 20: 3-7, 2005.

16. Staedel C and Darfeuille F: MicroRNAs and bacterial infection. Cell Microbiol 15: 1496-1507, 2013.

17. Kato M, Castro NE and Natarajan R: MicroRNAs: potential mediators and biomarkers of diabetic complications. Free Radic Biol Med 64: 85-94, 2013.

18. He L and Hannon GJ: MicroRNAs: Small RNAs with a big role in gene regulation. Nat Rev Genet 5: 522-531, 2004.

19. Filipowicz W: RNAi: The nuts and bolts of the RISC machine. Cell 122: 17-20, 2005

20. Latreille M, Hausser J, Stutzer I, Stützer I, Zhang Q, Hastoy B, Gargani S, Kerr-Conte J, Pattou F,Zavolan M, et al: MicroRNA-7a regulates pancreatic $\beta$ cell function. J Clin Invest 124: 2722-2735, 2014.

21. Poy MN, Eliasson L, Krutzfeldt J, Kuwajima S, Ma X, Macdonald PE, Pfeffer S, Tuschl T, Rajewsky N, Rorsman P and Stoffel M: A pancreatic islet-specific microRNA regulates insulin secretion. Nature 432: 226-230, 2004.

22. El Ouaamari A, Baroukh N, Martens GA, Lebrun P, Pipeleers D and van Obberghen E: miR-375 targets 3'-phosphoinositide-dependent protein kinase-1 and regulates glucose-induced biological responses in pancreatic beta-cells. Diabetes 57: 2708-2717, 2008.
23. Lovis P, Gattesco S and Regazzi R: Regulation of the expression of components of the exocytotic machinery of insulin-secreting cells by microRNAs. Biol Chem 389: 305-312, 2008.

24. Correa-Medina M, Bravo-Egana V, Rosero S, Ricordi C, Edlund H, Diez J and Pastori RL: MicroRNA miR-7 is preferentially expressed in endocrine cells of the developing and adult human pancreas. Gene Expr Patterns 9: 193-199, 2009.

25. Estep M, Armistead D, Hossain N, Elarainy H, Goodman Z, Baranova A, Chandhoke V and Younossi ZM: Differential expression of miRNAs in the visceral adipose tissue of patients with non-alcoholic fatty liver disease. Aliment Pharmacol Ther 32: 487-497, 2010.

26. Luo H, Zhang H, Zhang Z, Zhang X, Ning B, Guo J, Nie N, Liu B and Wu X: Down-regulated miR-9 and miR-433 in human gastric carcinoma. J Exp Clin Cancer Res 28: 82, 2009.

27. Chavali V, Tyagi SC and Mishra PK: Differential expression of dicer, miRNAs, and inflammatory markers in diabetic Ins2+/Akita hearts. Cell Biochem Biophys 68: 25-35, 2014.

28. Livak KJ and Schmittgen TD: Analysis of relative gene expression data using real-time quantitative PCR and the 2(-Delta Delta C(T)) Method. Methods 25: 402-408, 2001.

29. Jansen F, Wang H, Przybilla D, Franklin BS, Dolf A, Pfeifer P, Schmitz T, Flender A, Endl E, Nickenig G and Werner N: Vascular endothelial microparticles-incorporated microRNAs are altered in patients with diabetes mellitus. Cardiovasc Diabetol 15: 49, 2016.

30. Wang JM and Zhang K: Microarray analysis of microRNA expression in bone marrow-derived progenitor cells from mice with type 2 diabetes. Genom Data 7: 86-87, 2015.

31. Weir GC and Bonner-Weir S: Five stages of evolving beta-cell dysfunction during progression to diabetes. Diabetes 53 (Suppl 3): S16-S21, 2004

32. Xu X, Zhu Y, Liang Z, Li S, Xu X, Wang X, Wu J, Hu Z, Meng S, Liu B, et al: c-Met and CREB1 are involved in miR-433-mediated inhibition of the epithelial-mesenchymal transition in bladder cancer by regulating Akt/GSK-3//Snail signaling. Cell Death Dis 7: e2088, 2016.

33. Wang XC, Ma Y, Meng PS, Han JL, Yu HY and Bi LJ: miR-433 inhibits oral squamous cell carcinoma (OSCC) cell growth and metastasis by targeting HDAC6. Oral Oncol 51: 674-682, 2015.

34. Zhu D, Zhang L, Cheng L, Ren L, Tang J and Sun D: Pancreatic kininogenase ameliorates renal fibrosis in streptozotocin induced-diabetic nephropathy rat. Kidney Blood Press Res 41: 9-17, 2016.

35. Gotanda K, Hirota T, Matsumoto N and Ieiri I: MicroRNA-433 negatively regulates the expression of thymidylate synthase (TYMS) responsible for 5-fluorouracil sensitivity in HeLa cells. BMC Cancer 13: 369, 2013.

36. Greenhough A, Smartt HJ, Moore AE, Roberts HR, Williams AC, Paraskeva $\mathrm{C}$ and Kaidi A: The COX-2/PGE2 pathway: Key roles in the hallmarks of cancer and adaptation to the tumour microenvironment. Carcinogenesis 30: 377-386, 2009.

37. Papadimitriou A, King AJ, Jones PM and Persaud SJ: Anti-apoptotic effects of arachidonic acid and prostaglandin E2 in pancreatic beta-cells. Cell Physiol Biochem 20: 607-616, 2007.

38. Burke SJ, Karlstad MD, Regal KM, Sparer TE, Lu D, Elks CM, Grant RW, Stephens JM, Burk DH and Collier JJ: CCL20 is elevated during obesity and differentially regulated by $N F-\kappa B$ subunits in pancreatic $\beta$-cells. Biochim Biophys Acta 1849: 637-652, 2015.

39. Tabriz HM, Mirzaalizadeh M, Gooran S, Niki F and Jabri M: COX-2 expression in renal cell carcinoma and correlations with tumor grade, stage and patient prognosis. Asian Pac J Cancer Prev 17: 535-538, 2016. 